\title{
Both Quorum Sensing (Qs)-I and Ii Systems Regulate Escherichia coli Flagellin Expression
}

\author{
Yang Yang ${ }^{1,2}$, Yun Liu ${ }^{1}$, Mingxu Zhou ${ }^{1}$ and Guoqiang Zhu ${ }^{1, *}$ \\ ${ }^{1}$ Jiangsu Co-Innovation Center for Important Animal Infectious Diseases and \\ Zoonoses, College of Veterinary Medicine, Yangzhou University, Yangzhou 225009, \\ China \\ ${ }^{2}$ Institute of Epigenetics and Epigenomics and College of Animal Science and \\ Technology, Yangzhou University, Yangzhou 225009, China
}

\section{A B S T R A C T}

For elucidating effect of quorum sensing (QS) systems I and II (QS-1 and QS-II) on Escherichia coli flagellin expression, E. coli F18ab strain 107/86 was modified to either express acyl-homoserine lactone (AHL) synthase (QS-I) or deleted for autoinducer 2 (AI-2) expression (QS-II). AHL expression and deletion of luxS (AI-2) both inhibited flagellin expression, as measured by motility assays, bacterial gene expression, and host responses to infection. The QS systems and flagellin were coordinately regulated, as deleting $\mathrm{fliC}$ caused decreased QS-II activity.

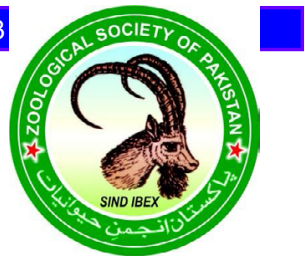

\begin{tabular}{l} 
CrossMark \\
Article Information \\
\hline Received 23 May 2018 \\
Revised 27 June 2018 \\
Accepted 24 July 2018 \\
Available online 04 August 2018 \\
Authors' Contribution \\
\hline GZ designed the study. YY performed \\
experimental work, analyzed the data \\
and wrote the article. YL helped in \\
motility assays. MZ helped in article \\
writing. \\
Key words \\
\hline E.coli, Flagellin, Quorum sensing-I \\
and II.
\end{tabular}

\section{INTRODUCTION}

$\mathrm{P}$ orcine edema disease and porcine post-weaning diarrhea are two important diseases which bring pigs high morbidity and mortality. Shiga toxin-producing E. coli (STEC) is major pathogen of the diseases (Da et al., 2001; Frydendahl, 2002). Flagella participate in bacterial pathogenicity as important virulence factor. Besides providing motility, it also contributes to bacterial initial adhesion or colonization to host cells. In vivo, enteric bacteria could take advantage of flagella motility to compete with intestinal microbiota by exploiting inflammation (Stecher et al., 2004, 2008; Duan et al., 2012; Zhou et al., 2013).

Quorum sensing (QS) represents one crucial communication system, and was considered as a kind of bacterial-population based language between bacteria (Pacheco and Sperandio, 2009; Curtis and Sperandio, 2011). QS-I positive bacteria normally express acylhomoserine lactone (AHL) synthase, whereas the QS-II system is regulated by LuxS and autoinducer 2 (AI-2) (Niu et al., 2013). We previously reported that QS-I expression in E. coli suppresses flagella expression (Yang et al., 2013). QS-II also regulates bacterial virulence strategies, including regulate motility by $f h D C$, type III secretion systems (Anand and Griffiths, 2003; Li et al., 2007; Han and $\mathrm{Lu}, 2009$ ), as well as biofilm formation and bacterial

\footnotetext{
Corresponding author: yzgqzhu@yzu.edu.cn; yzgqzhu@hotmail.com 0030-9923/2018/0005-1807 \$ 9.00/0

Copyright 2018 Zoological Society of Pakistan
}

pathogenicity (Sperandio et al., 2002; Clarke et al., 2006; Gonzalez et al., 2006).

Here we investigated the extent to which QS-II can also regulate flagellin expression in STEC and examined the potential for coordinate regulation between two QS systems.

\section{MATERIALS AND METHODS}

Strains used in this study

Strains and plasmids used are listed in Table I. LB broth or LB agar plates were used for bacterial growth. Caco-2 cell line was cultivated in DMEM with $10 \%$ FBS $\left(37{ }^{\circ} \mathrm{C}, 5 \% \mathrm{CO}_{2}\right)$. Human TNF and IL-8 immunoassay Kits (R\&D Systems, Inc.) were purchased for relative experiments.

\section{Construction of recombinant strains}

The F18ab luxS gene in-frame deletion mutant (F18abAluxS) was constructed using $\lambda$ Red-based recombination system (Datsenko and Wanner, 2000). The luxS open reading frame (ORF) was amplified by primers LuxS-1/ LuxS-2 (Table II). Plasmid pBR-luxS was constructed and then transformed into F18ab $\Delta l u x S$ to obtain the complemented strain F18ab $\Delta l u x S /$ pluxS.

To over-express $u v r Y$ and $\operatorname{csr} B$ in F18ab, the primers $u v r Y-\mathrm{F} / u v r Y-\mathrm{R}$ and $\operatorname{csr} B-\mathrm{F} / \operatorname{csr} B-\mathrm{R}$ were used to PCR amplify $u v r Y$ and $\operatorname{csr} B$, respectively. $u v r Y$ and $\operatorname{csr} B$ were cloned into pBR322 and transformed into F18ab E. coli.

\section{AI-2 bioassays and motility assays}

After grown to an OD600 of 1.3, supernatants of 
strains were collected. Bioluminescence was measured in luminescence mode by Tecan GPM reader (Han and Lu, 2009; Zhou et al., 2014). For motility assays, strains were seeded in the middle of motility agar plates. After appropriate growth time, motility halos were measured (Duan et al., 2013).

Table I.- Strains and plasmids used in this study.

\begin{tabular}{|c|c|c|}
\hline Strain or plasmid & Description & Source or reference \\
\hline \multicolumn{3}{|l|}{ Strains } \\
\hline E. coli F18ab 107/86 & $\begin{array}{l}\text { Wild-type: } \\
\text { O139:H1:F18ab, Stx2e; O139:H1:F18ab, Stx2e }\end{array}$ & Duan et al. (2012) \\
\hline E. coli $\mathrm{F} 18 \mathrm{ab} /$ pyenI & 107/86 carrying pyenI & Yang et al. (2013) \\
\hline E. coli $\mathrm{F} 18 \mathrm{ab} / \mathrm{pBR}$ & 107/86 carrying pBR322 & Yang et al. (2013) \\
\hline E. coli $\mathrm{F} 18 \mathrm{ab} \Delta \mathrm{fliC}$ & $\mathrm{fliC}$ deletion mutant & Duan et al. (2012) \\
\hline E. coli $\mathrm{F} 18 \mathrm{ab} \Delta$ fliC/pfliC & $\mathrm{F} 18 \mathrm{ab} \Delta f l i C$ carrying $\mathrm{pBR}-f l i C$ & Duan et al. (2012) \\
\hline E. coli F18ab $\Delta$ luxS & luxS deletion mutant & This study \\
\hline E. coli $\mathrm{F} 18 \mathrm{ab} \Delta \mathrm{luxS} / \mathrm{pluxS}$ & F18ab $\Delta l u x S$ carrying pBR-luxS & This study \\
\hline E. coli $\mathrm{F} 18 \mathrm{ab} / \mathrm{pcsrB}$ & $107 / 86$ carrying $\mathrm{p} c s r B$ & This study \\
\hline E. coli F18ab/puvrY & 107/86 carrying $\mathrm{p} u v r Y$ & This study \\
\hline E. coli $\mathrm{DH} 5 a$ & AI-2 bioassay negative control & Takara Ltd. \\
\hline Vibrio harveyi $\mathrm{BB} 170$ & AI-2 bioassay reporter strain & Bassler et al. (1994); Yang et al. (2013) \\
\hline \multicolumn{3}{|l|}{ Plasmids } \\
\hline pBR322 & Expression vector, $A m p^{r}$ & Takara Ltd. \\
\hline pBR-luxS & pBR322 carrying LuxS ORF & This study \\
\hline pKD3 & $\mathrm{Cm}^{\mathrm{r}} ; \mathrm{Cm}$ cassette template & Datsenko and Wanner (2000); Duan et al. (2012) \\
\hline pKD46 & $A m p^{r}, \lambda$ Red recombinase expression & Datsenko and Wanner (2000); Duan et al. (2012) \\
\hline pCP20 & $\mathrm{Amp}^{\mathrm{r}}, \mathrm{Cm}^{\mathrm{r}}$; Flp recombinase expression & Datsenko and Wanner (2000); Duan et al. (2012) \\
\hline
\end{tabular}

Table II.- Primers used in this study.

\begin{tabular}{|c|c|c|c|}
\hline Primer & Sequence (5'-3') & Primer & Sequence (5'-3') \\
\hline LuxS-1 & ATGCCGTTGTTAGATAGCTTCAC & $\operatorname{csr} A-R T-\mathrm{F}$ & AGCCTGGATACGCTGGTAGA \\
\hline LuxS-2 & CTAGATGTGCAGTTCCTGCAACT & $\operatorname{csr} A-R T-\mathrm{R}$ & CGAGTTGGTGAGACCCTCAT \\
\hline \multirow[t]{3}{*}{$\Delta L u x S-1$} & \multirow{3}{*}{$\begin{array}{l}\text { TGCAGTTCGGGTGGCGAAAACAATGA } \\
\text { ACACCCCGCATGGCGACGCAATCATGT } \\
\text { GTAGGCTGGAGCTGCTTCG }\end{array}$} & barA-RT-F & GCTGCGTACACCACTGAATG \\
\hline & & barA-RT-R & TGCGTAGTGGGAATGGAATAC \\
\hline & & $f l i C-R T-\mathrm{F}$ & CAGCAAGCGGTGAAGTGAA \\
\hline \multirow[t]{3}{*}{$\Delta$ LuxS-2 } & \multirow{3}{*}{$\begin{array}{l}\text { TCTGATTCTGATCCTGCACTTTCAGCAC } \\
\text { GTCTTCCATTGCCGCTTTCCCATATGAAT } \\
\text { ATCCTCCTTAG }\end{array}$} & $f l i C-R T-\mathrm{R}$ & AAGCGTAGCCACAGTAGCA \\
\hline & & $f h D-R T-\mathrm{F}$ & ACTGACTCTTCCGCAAATGGT \\
\hline & & $f h D-R T-\mathrm{R}$ & TGGCTGTCAAAACGGAAGTG \\
\hline$u v r Y-F$ & TAAGGATCCATGGACATGAGTAT & $i l 8-R T-\mathrm{F}$ & TGCAGCTCTGTGTGAAGGTG \\
\hline$u v r Y-\mathrm{R}$ & TTAGTCGACTCACTGACTTGATAAT & $i l 8-R T-\mathrm{R}$ & ACTTCTCCACAACCСТCTGC \\
\hline $\operatorname{csr} B-\mathrm{F}$ & TAAGGATCCGTCGACAGGGAGT & illo-RT-F & CCACGCTTTCTAGCTGTTGA \\
\hline $\operatorname{csr} B-\mathrm{R}$ & CGCGTCGACAATAAAAAAAGGG & $i l 10-R T-\mathrm{R}$ & CTCCGAGACACTGGAAGGTG \\
\hline gapA-RT-F & CGTTAAAGGCGCTAACTTCG & tnfa-RT-F & CCCAGGGACCTCTCTCTAATC \\
\hline gapA-RT-R & ACGGTGGTCATCAGACCTTC & tnfa-RT-R & TGAGGTACAGGCCCTCTGAT \\
\hline$u v r Y-R T-\mathrm{F}$ & TACCAGCGAAAGTCATGCAG & GAPDH-RT-F & GATGGGCGTGAACCATGAG \\
\hline uvr Y-RT-R & CGTTCAGACAAACTGGCAAA & GAPDH-RT-R & GAGGCATTGCTGACGATCTTG \\
\hline
\end{tabular}



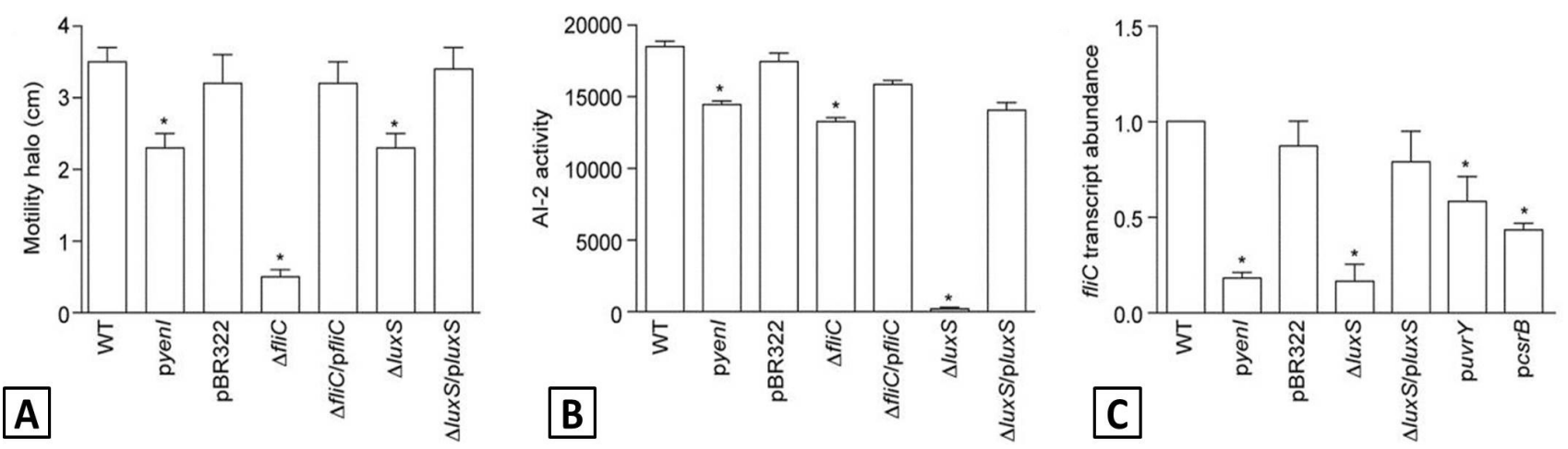

Fig. 1. QS-1 and QS-II have differential impact on bacterial motility. A, motility diameters were quantified after $12 \mathrm{~h}$ growth on $0.3 \%$ swim agar plates; $\mathrm{B}, \mathrm{AI}-2$ production, $\mathrm{AI}-2$ activity was measured using a bioluminescence assay after growing the indicated bacterial strains to an $\mathrm{OD}_{600}$ of 1.3 . AI-2 activity is expressed as relative light units measured; $\mathrm{C}, \mathrm{fliC}$ expression. fliC expression was measured using qRT-PCR with data normalized to the endogenous reference gene gapA. Data are expressed relative to expression in the WT strain.

\section{Measurement of mRNA level}

Tiangen RNA Extraction Kit (DP419) was employed in this study, through which total RNA from each strain was prepared (Han and $\mathrm{Lu}, 2009$ ). Primers for $f h D, f l i C$, csr A, barA, uvrY, pfs, and luxS genes were designed and listed in Table II. Gene gapA was chosen as the endogenous reference. Caco- $2\left(1 \times 10^{6}\right.$ cells/well density $)$ was plated in 6-well plates. $10^{7} \mathrm{CFU}$ of relative strains were injected into each well, and infected for $2 \mathrm{~h}$. Then cells were dealt with Tiangen RNA Extraction Kit following the standard protocol. $2^{-\Delta \Delta C T}$ method was employed for data analysis.

\section{ELISA assay}

Monolayer of Caco-2 was prepared for infection of individual E. coli strains. After $2 \mathrm{~h}$ incubation, supernatants were obtained by centrifugation (Duan et al., 2012). With commercial kits, expression levels of IL- 8 and TNF were then measured.

\section{Statistics}

All experiments were repeated at least 3 times. Data are presented as the mean \pm standard deviation. To evaluate statistical significance with $p<0.05$ considered significant, the Student's t-test method was employed.

\section{RESULTS AND DISCUSSION}

QS-1 and QS-II have differential impact on bacterial motility and affect E. coli-induced pro-inflammatory responses

F18ab E. coli was transformed with the yenI gene from $Y$. enterocolitica to induce endogenous AHL production (QS-1) (Yang et al., 2013). Flagella involves in bacterial motility, adhesion, invasion. Furthermore, it could induce inflammation response in host cells. With the recombinant strain, function of AHL (QS-1 signals) upon flagella expression could be identified. Subsequently, expressing pyenI inhibited bacterial motility on swim agar plates (Fig. 1A). Reduced flagella expression was observed in AHL positive strain F18ab/pyenI, as well as decreased motility ability.

QS-II manipulates multiple genes expression through AI-2. In many pathogenic bacteria, AI-2 participates in regulating bacterial virulence strategies. To assess a similar role for QS-2 on motility, we deleted the luxS gene. F18ab $\Delta l u x S$ was deficient in AI-2 production (Fig. 1B) and was less motile than the WT strain (Fig. 1A). Consistent with their impaired motility, $f i C$ expression was inhibited in both pyenI and in $\Delta l u x S$ (Fig. 1C).

Bacterial flagellin can induce pro-inflammatory responses through TLR5. TLR5 stimulates proinflammatory genes in NF- $\mathrm{KB}$ and MAPK pathways (Vijay-Kumar et al., 2010; Salazar-Gonzalez and NavarroGarcia, 2011). Researchers found that as one pathogenassociated molecular pattern (PAMP), flagellin also have TLR5-independent pro-inflammatory ability by Naip5 and Ipaf, members of the NLR family (Miao et al., 2006; Ren et al., 2006).

These F18ab E. coli strains did not activate the proinflammatory IL-8 or TNF responses of infected Caco2 cells to a magnitude equal to that of infection by WT F18ab E. coli, as measured by both RT-PCR (Fig. 2A, B) or by ELISA (Fig. 2C, D). QS-1 expression inhibits F18 E. coli motility, whereas QS-II expression enhances motility by affecting $f i C$ expression. 

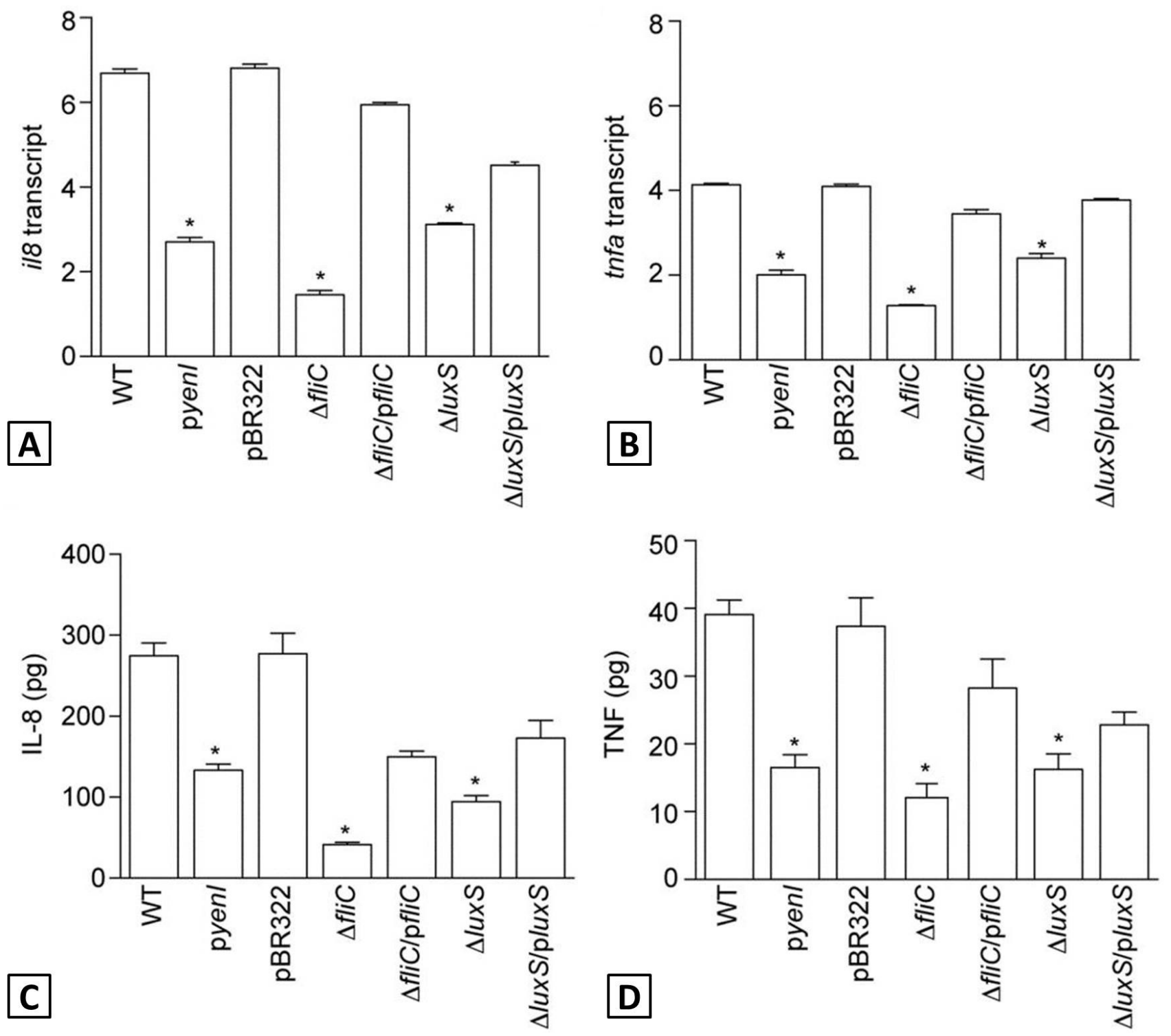

Fig. 2. Host IL-8 and TNF expression in response to F18 E. coli infection. A-B, transcription of $i l 8$ and tnfa in Caco-2 cells after a $2 \mathrm{~h}$ infection with the indicated bacterial strains. Data were normalized to the housekeeping gene gapdh; C-D, ELISA, secretion of IL-8 and TNF into Caco- 2 cell supernatants after a $2 \mathrm{~h}$ infection with the indicated bacterial strains was quantified using ELISAs.

\section{AI-1 and flagella expression influence AI-2}

AI-2 activity was impaired in F18ab/pyenI, indicating that QS-1 influences AI-2 production (Fig. 1B). The phenomenon was consistent with the decreased mRNA level of both $\operatorname{luxS}$ and $p f s$ in F18ab/pyenI (Fig. 3), which encode enzymes involved in AI-2 synthesis in $E$. coli (Zhu et al., 2007). $P f_{s}$, an important functional enzyme in AI-2 signal synthesis, encounter $25 \%$ decrease of mRNA level under QS-1 influence, while flagella motility was reduced heavily in luxS mutant. FliC expression also regulated QSII, as deleting $f l i C$ inhibited $p f s$ and $l u x S$ expression (Fig. 3).
Coordinate regulation of flagella and QS expression

Bacteria utilize two-component systems for adaptation to environmental changes (Pernestig et al., 2001, 2003; Herren et al., 2006; Yang et al., 2014). The BarA/UvrY and the CsrA/CsrB two-component systems regulate flagella expression (Edwards et al., 2011). UvrY can activate barA expression through an auto-regulatory loop. Influence of CsrA upon $\operatorname{csr} B$ is regulated partly by $\operatorname{bar} A$, and a BarA-independent, UvrY-dependent mechanism also involves. CsrA indirectly induces $\operatorname{csr} B$ transcription. UvrY can directly activate $\operatorname{csr} B$ transcription, and also is 
included in up-regulation of CsrA. Increased transcription of $u v r Y$ has been observed when E. coli is sustained in an AHL-positive environment (Wei et al., 2001; Van Houdt et al., 2006).

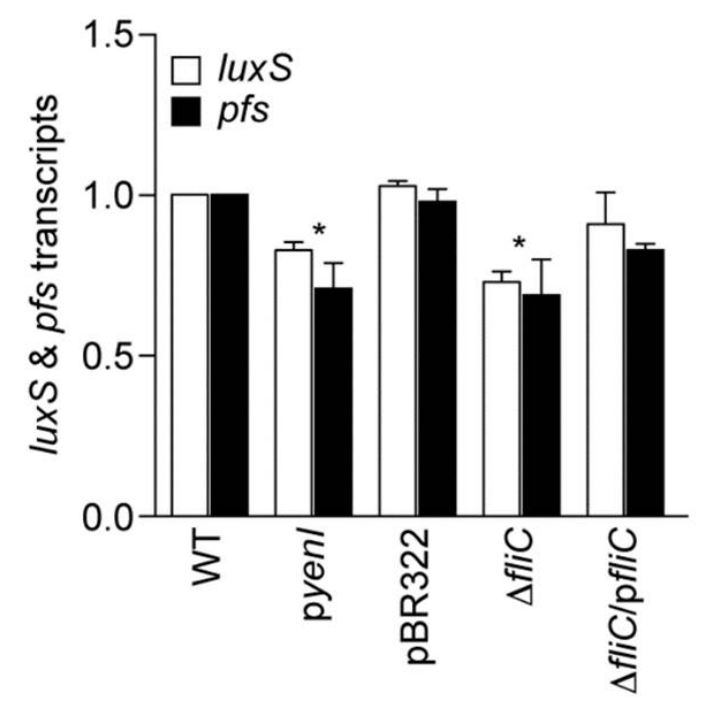

Fig. 3. AI-1 and flagella expression influence AI-2 expression. $\operatorname{lu} x S$ and $p f s$ expression were measured using qRT-PCR with data normalized to the endogenous reference gene gapA. Data are expressed relative to expression in the WT strain.

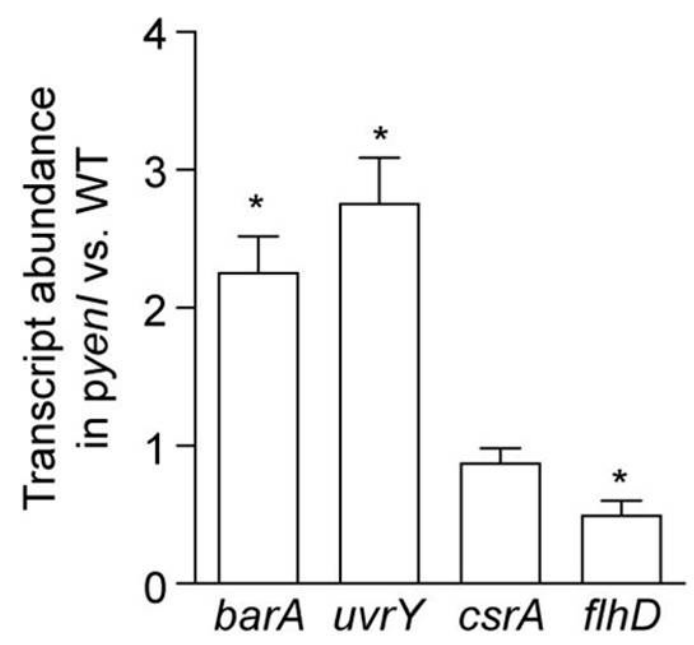

Fig. 4. Coordinate regulation of flagella and QS expression. Transcription of the indicated genes was measured using qRT-PCR. Data are shown as expression in pyenI vs. WT.

In this study, expression of barA and $u v r Y$ were increased by 2.3- and 2.7-fold, respectively, in F18ab/ pyenI (Fig. 4). Up-regulation of $u v r Y$ and barA can induce $\operatorname{csr} B$ transcription, which binds to CsrA and antagonizes its regulatory effects upon $f h D C$ (Liu and Romeo, 1997; Mercante et al., 2009; Edwards et al., 2011). fhD expression did decreased 2.1-fold in pyenI (Fig. 4). Overexpressing $u v r Y$ and $\operatorname{csr} B$ caused a 1.7- and 2.3-fold reduction in $f i C$ expression, respectively (Fig. 1C).

\section{CONCLUSIONS}

Overall, we show here that expressing QS-1 in $E$. coli inhibits flagella expression, whereas the LuxS QS-II system up-regulates flagella expression. These systems are coordinately regulated, as QS-I inhibited QS-II and flagellin expression positively regulated LuxS. We implicate the BarA/UvrY and the CsrA/CsrB two-component systems as possible regulators of this coordinated regulation. In the presence of cattle rumen AHLs, E. coli O157:H7 represses $L E E$ gene expression and activates gad expression to improve acid tolerance (Sperandio, 2010; Sheng et al., 2013). Other aspects of $E$. coli biology are also regulated by AHLs, including cell division (Sitnikov et al., 1996) and antibiotic resistance (Rahmati et al., 2002). These data suggest that $E$. coli flagella expression is also regulated by AHLs.

\section{ACKNOWLEDGEMENTS}

This study was supported by grants from the 13th Five-Year National Key Development Program (2016YFD0501000), Natural Science Foundation of Jiangsu Province (BK20150442), the Chinese National Science Foundation Grants (Nos. 31502075, 31072136, 31270171 and 30771603), the Genetically Modified Organisms Technology Major Project of China (2014ZX08006-001B), Program for Chang Jiang Scholars and Innovative Research Team In University "PCSIRT" (IRT0978), 948 programme from Ministry of Agriculture of the People's Republic of China (grant No. 2011-G24) and the Priority Academic Program Development of Jiangsu Higher Education Institutions.

\section{Statement of conflict of interest}

The authors or their institution do not have any relationships that may influence or bias the results and data presented in this manuscript. There is no conflict of interests regarding the publication of the manuscript.

\section{REFERENCES}

Anand, S.K. and Griffiths, M.W., 2003. Quorum sensing and expression of virulence in Escherichia coli O157:H7. Int. J. Fd. Microbiol., 85: 1-9. https:// doi.org/10.1016/S0168-1605(02)00482-8 
Bassler, B.L., Wright, M. and Silverman, M.R., 1994. Multiple signalling systems controlling expression of luminescence in Vibrio harveyi: sequence and function of genes encoding a second sensory pathway. Mol. Microbiol., 13: 273-286. https://doi. org/10.1111/j.1365-2958.1994.tb00422.x

Clarke, M.B., Hughes, D.T., Zhu, C., Boedeker, E.C. and Sperandio, V., 2006. The QseC sensor kinase: a bacterial adrenergic receptor. Proc. natl. Acad. Sci. USA, 103: 10420-10425. https://doi.org/10.1073/ pnas.0604343103

Curtis, M.M. and Sperandio, V., 2011. A complex relationship: The interaction among symbiotic microbes, invading pathogens, and their mammalian host. Mucosal. Immunol., 4: 133-138. https://doi. org/10.1038/mi.2010.89

Da, S.A., Valadares, G.F., Penatti, M.P., Brito, B.G. and Da, S.L.D., 2001. Escherichia coli strains from edema disease: $\mathrm{O}$ serogroups, and genes for Shiga toxin, enterotoxins, and F18 fimbriae. Vet. Microbiol., 80: 227-233. https://doi.org/10.1016/ S0378-1135(01)00316-9

Datsenko, K.A. and Wanner, B.L., 2000, One-step inactivation of chromosomal genes in Escherichia coli K-12 using PCR products. Proc. natl. Acad. Sci. USA, 97: 6640-6645. https://doi.org/10.1073/ pnas. 120163297

Duan, Q., Zhou, M., Zhu, L. and Zhu, G., 2012. Flagella and bacterial pathogenicity. J. Basic Microbiol., 52: 1-8.

Duan, Q., Zhou, M., Zhu, X., Bao, W., Wu, S., Ruan, X., Zhang, W., Yang, Y., Zhu, J. and Zhu, G., 2012. The flagella of F18ab Escherichia coli is a virulence factor that contributes to infection in a IPEC-J2 cell model in vitro. Vet. Microbiol., 160: 132-140. https://doi.org/10.1016/j.vetmic.2012.05.015

Duan, Q., Zhou, M., Zhu, X., Yang, Y., Zhu, J., Bao, W., Wu, S., Ruan, X., Zhang, W. and Zhu, G., 2013. Flagella from F18+Escherichia coli play a role in adhesion to pig epithelial cell lines. Microb. Pathog., 55: 32-38. https://doi.org/10.1016/j. micpath.2012.09.010

Edwards, A.N., Patterson-Fortin, L.M., Vakulskas, C.A., Mercante, J.W., Potrykus, K., Vinella, D., Camacho, M.I., Fields, J.A., Thompson, S.A., Georgellis, D., Cashel, M., Babitzke, P. and Romeo, T., 2011. Circuitry linking the Csr and stringent response global regulatory systems. Mol. Microbiol., 80: 1561-1580. https://doi.org/10.1111/ j.1365-2958.2011.07663.x

Frydendahl, K., 2002. Prevalence of serogroups and virulence genes in Escherichia coli associated with postweaning diarrhoea and edema disease in pigs and a comparison of diagnostic approaches. Vet.
Microbiol., 85: 169-182. https://doi.org/10.1016/ S0378-1135(01)00504-1

Gonzalez, B.A., Zuo, R., Hashimoto, Y., Yang, L., Bentley, W.E. and Wood, T.K., 2006, Autoinducer 2 controls biofilm formation in Escherichia coli through a novel motility quorum-sensing regulator (MqsR, B3022). J. Bact., 188: 305-316. https://doi. org/10.1128/JB.188.1.305-316.2006

Han, X.G. and Lu, C.P., 2009. Detection of autoinducer-2 and analysis of the profile of luxS and pfs transcription in Streptococcus suis serotype 2. Curr. Microbiol., 58: 146-152. https://doi.org/10.1007/ s00284-008-9291-9

Herren, C.D., Mitra, A., Palaniyandi, S.K., Coleman, A., Elankumaran, S. and Mukhopadhyay, S., 2006. The BarA-UvrY two-component system regulates virulence in avian pathogenic Escherichia coli O78:K80:H9. Infect. Immun., 74: 4900-4909. https://doi.org/10.1128/IAI.00412-06

Li, J., Attila, C., Wang, L., Wood, T.K., Valdes, J.J. and Bentley, W.E., 2007. Quorum sensing in Escherichia coli is signaled by AI-2/LsrR: Effects on small RNA and biofilm architecture. J. Bact., 189: 6011-6020. https://doi.org/10.1128/JB.0001407

Liu, M.Y. and Romeo, T., 1997. The global regulator CsrA of Escherichia coli is a specific mRNAbinding protein. J. Bact., 179: 4639-4642. https:// doi.org/10.1128/jb.179.14.4639-4642.1997

Mercante, J., Edwards, A.N., Dubey, A.K., Babitzke, P. and Romeo, T., 2009. Molecular geometry of CsrA (RsmA) binding to RNA and its implications for regulated expression. J. mol. Biol., 392: 511-528. https://doi.org/10.1016/j.jmb.2009.07.034

Miao, E.A., Alpuche-Aranda, C.M., Dors, M., Clark, A.E., Bader, M.W., Miller, S.I. and Aderem, A., 2006. Cytoplasmic flagellin activates caspase-1 and secretion of interleukin 1beta via Ipaf. Nat. Immunol., 7: 569-575. https://doi.org/10.1038/ ni1344

Niu, C., Robbins, C.M., Pittman, K.J., Osborn, J., Stubblefield, B.A., Simmons, R.B. and Gilbert, E.S., 2013. LuxS influences Escherichia coli biofilm formation through autoinducer-2-dependent and autoinducer-2-independent modalities. FEMS Microbiol. Ecol., 83: 778-791. https://doi. org/10.1111/1574-6941.12034

Pacheco, A.R. and Sperandio, V., 2009. Inter-kingdom signaling: Chemical language between bacteria and host. Curr. Opin. Microbiol., 12: 192-198. https:// doi.org/10.1016/j.mib.2009.01.006

Pernestig, A.K., Georgellis, D., Romeo, T., Suzuki, K., Tomenius, H., Normark, S. and Melefors, O., 2003. The Escherichia coli BarA-UvrY two-component 
system is needed for efficient switching between glycolytic and gluconeogenic carbon sources. J. Bact., 185: 843-853. https://doi.org/10.1128/ JB.185.3.843-853.2003

Pernestig, A.K., Melefors, O. and Georgellis, D., 2001. Identification of UvrY as the cognate response regulator for the BarA sensor kinase in Escherichia coli. J. biol. Chem., 276: 225-231. https://doi. org/10.1074/jbc.M001550200

Rahmati, S., Yang, S., Davidson, A.L. and Zechiedrich, E.L., 2002. Control of the AcrAB multidrug efflux pump by quorum-sensing regulator SdiA. Mol. Microbiol., 43: 677-685. https://doi.org/10.1046/ j.1365-2958.2002.02773.x

Ren, T., Zamboni, D.S., Roy, C.R., Dietrich, W.F. and Vance, R.E., 2006. Flagellin-deficient Legionella mutants evade caspase-1- and Naip5-mediated macrophage immunity. PLoS Pathog., 2: e18. https://doi.org/10.1371/journal.ppat.0020018

Salazar-Gonzalez, H. and Navarro-Garcia, F., 2011. Intimate adherence by enteropathogenic Escherichia coli modulates TLR5 localization and proinflammatory host response in intestinal epithelial cells. Scand. J. Immunol., 73: 268-283. https://doi.org/10.1111/j.1365-3083.2011.02507.x

Sheng, H., Nguyen, Y., Hovde, C.J. and Sperandio, V., 2013. SdiA aids enterohemorrhagic E. coli carriage by cattle fed forage or grain diets. Infect. Immun., 81: 3472-3478. https://doi.org/10.1128/IAI.0070213

Sitnikov, D.M., Schineller, J.B., and Baldwin, T.O., 1996. Control of cell division in Escherichia coli: Regulation of transcription of ftsQA involves both rpoS and SdiA-mediated autoinduction. Proc. natl. Acad. Sci. USA, 93: 336-341. https://doi. org/10.1073/pnas.93.1.336

Sperandio, V., 2010. SdiA sensing of acyl-homoserine lactones by enterohemorrhagic E. coli (EHEC) serotype O157:H7 in the bovine rumen. Gut Microbes, 1: 432-435. https://doi.org/10.4161/ gmic.1.6.14177

Sperandio, V., Torres, A.G. and Kaper, J.B., 2002. Quorum sensing Escherichia coli regulators B and C (QseBC): A novel two-component regulatory system involved in the regulation of flagella and motility by quorum sensing in E. coli. Mol. Microbiol., 43: 809-821. https://doi.org/10.1046/ j.1365-2958.2002.02803.x

Stecher, B., Barthel, M., Schlumberger, M.C., Haberli, L., Rabsch, W., Kremer, M. and Hardt W.D., 2008. Motility allows $S$. typhimurium to benefit from the mucosal defence. Cell Microbiol., 10: 1166-1180. https://doi.org/10.1111/j.1462-5822.2008.01118.x
Stecher, B., Hapfelmeier, S., Muller, C., Kremer, M., Stallmach, T. and Hardt, W.D., 2004. Flagella and chemotaxis are required for efficient induction of Salmonella enterica serovar Typhimurium colitis in streptomycin-pretreated mice. Infect. Immun., 72: 4138-4150. https://doi.org/10.1128/IAI.72.7.41384150.2004

Van Houdt, R., Aertsen, A., Moons, P., Vanoirbeek, K. and Michiels, C.W., 2006. N-acyl-L-homoserine lactone signal interception by Escherichia coli. FEMS Microbiol. Lett., 256: 83-89. https://doi. org/10.1111/j.1574-6968.2006.00103.x

Vijay-Kumar, M., Carvalho, F.A., Aitken, J.D., Fifadara, N.H. and Gewirtz, A.T., 2010. TLR5 or NLRC4 is necessary and sufficient for promotion of humoral immunity by flagellin. Eur. J. Immunol., 40: 35283534. https://doi.org/10.1002/eji.201040421

Wei, Y., Lee, J.M., Smulski, D.R. and LaRossa, R.A., 2001, Global impact of sdiA amplification revealed by comprehensive gene expression profiling of Escherichia coli. J. Bact., 183: 2265-2272. https:// doi.org/10.1128/JB.183.7.2265-2272.2001

Yang, Y., Yao, F., Zhou, M., Zhu, J., Zhang, X., Bao, W., Wu, S., Hardwidge, P.R. and Zhu, G., 2013. F18ab Escherichia coli flagella expression is regulated by acyl-homoserine lactone and contributes to bacterial virulence. Vet. Microbiol., 165: 378-383.

Yang, Y., Zhou, M., Hou, H., Zhu, J., Yao, F., Zhang, X., Zhu, X., Hardwidge, P.R. and Zhu, G., 2014. Quorum-sensing gene luxS regulates flagella expression and Shiga-like toxin production in F18ab Escherichia coli. Can. J. Microbiol., 60: 355-361. https://doi.org/10.1139/cjm-2014-0178

Zhou, M., Duan, Q., Zhu, X., Guo, Z., Li, Y., Hardwidge, P.R. and Zhu, G., 2013. Both flagella and F4 fimbriae from $\mathrm{F} 4 \mathrm{ac}+$ enterotoxigenic Escherichia coli contribute to attachment to IPEC-J2 cells in vitro. Vet. Res., 44: 30. https://doi. org/10.1186/1297-9716-44-30

Zhou, M., Guo, Z., Yang, Y., Duan, Q., Zhang, Q., Yao, F., Zhu, J., Zhang, X., Hardwidge, P.R. and Zhu, G., 2014. Flagellin and F4 fimbriae have opposite effects on biofilm formation and quorum sensing in F4ac+ enterotoxigenic Escherichia coli. Vet. Microbiol., 168: 148-153. https://doi.org/10.1016/j. vetmic.2013.10.014

Zhu, C., Feng, S., Sperandio, V., Yang, Z., Thate, T.E., Kaper, J.B. and Boedeker, E.C., 2007. The possible influence of LuxS in the in vivo virulence of rabbit enteropathogenic Escherichia coli. Vet. Microbiol., 125: 313-322. https://doi.org/10.1016/j. vetmic. 2007.05 .030 